\title{
Temperature decrease in the extratropics of South America in response to a tropical forcing during the austral winter
}

\author{
G. V. Müller \\ Centro de Investigaciones Científicas y Transferencia de Tecnología a la Producción, Diamante (CICYTTP-CONICET), Entre \\ Ríos, Argentina
}

Received: 9 June 2009 - Revised: 30 October 2009 - Accepted: 4 December 2009 - Published: 8 January 2010

\begin{abstract}
This paper focuses on the dynamic mechanisms that create favorable conditions for the occurrence of frosts that affect large areas of Argentina and are denominated generalized frosts (GF). The hemispheric teleconnection patterns linked to extreme cold events affecting central and northeastern Argentina during winter are identified. The objective is to determine whether the conditions found in previous studies for the composite of winters with extreme (maximum and minimum) frequency of GF occurrence respond to typical characteristics of the austral winter or they are inherent to those particular winters. Taking the mean winter as basic state in the 1961-1990 period, a series of numerical experiments are run using a primitive equation model in which waves are excited with a thermal forcing. The positions of the thermal forcing are chosen according to observed convection anomalies in a basic state given by the austral winters with extreme frequency of GF occurrence.
\end{abstract}

The wave trains excited by anomalous convection situated in specific regions may propagate across the Pacific Ocean and reach South America with the appropriate phase, creating the local favorable conditions for the occurrence of GF. However, the anomalous convection is, by itself, not sufficient since the response also depends on the basic state configuration. This is proved by placing the forcing over the region of significant anomalous convection for maximum and minimum frequency of GF occurrence and the response was very different in comparison to the mean winter. It is concluded that the conditions for a greater GF frequency of occurrence are inherent to these particular winters, so that such conditions are not present in the average winter.

Keywords. Meteorology and atmospheric dynamics (Climatology; General circulation; Middle atmosphere dynamics)

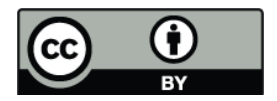

Correspondence to: G. V. Müller (gabrielamuller@ cicyttp.org.ar)

\section{Introduction}

During the past decades there have been great advances in understanding the mechanisms associated to temperature decrease in the extratropics of South America. Papers such as Krishnamurti et al. (1999), Marengo et al. (1997), Garreaud (2000), Vera et al. (2002), Pezza and Ambrizzi (2005), Müller and Berri (2007), among others, show the synoptic and dynamic characteristics of the cold outbreaks. The frosts which occur during these air irruptions can cause great damages to the agriculture of the regions affected, with a high impact on regional and national economies, mainly when these irruptions are very intense and/or persistent and of great latitudinal penetration. Therefore, it is important the diagnosis and forecasting of such events as well as to determine the precursory mechanisms through atmospheric teleconnections.

In relation to that, many papers have analyzed the linear response of a stratified atmosphere to a tropical thermal forcing, demonstrating the existence of a relationship between the warm anomalies in the tropics and circulation patterns in the extra-tropics. For example, Marengo et al. (2002) showed that quasi stationary Rossby waves coming from the western tropical Pacific during the austral winter, represent an important mechanism in the tropical-extratropical interaction which affects weather and climate in southeastern South America (SSA). In particular, the results of Müller et al. (2008) suggest that stationary Rossby waves may be the main mechanism linking anomalous tropical convection in the western Pacific Ocean with the extreme cold events in Argentina during the austral winter. The association of tropical convection and a specific basic state can generate the appropriate environment to guide towards South America the Rossby waves that have been triggered by the tropical forcing. The basic state used for these experiments is a composite of the austral winters with maximum and minimum frequency of occurrence of generalized frosts (GF). These are composed, respectively, by the winters where the number of GF is one standard deviation unit above $(+\sigma)$ and below

Published by Copernicus Publications on behalf of the European Geosciences Union. 
$(-\sigma)$ the mean value for the period 1961-1990. These GF affect a large area in the central and eastern part of Argentina, known as the Wet Pampa. GF is defined when the percentage of meteorological stations with frost (days during which surface temperature is equal to or less than $0^{\circ} \mathrm{C}$ ) is equal to or more than $75 \%$ (Müller et al., 2000).

The result of the experiment in the $+\sigma$ basic state with the heat source located in the position where a significant anomalous convection was observed (Pacific Ocean), showed negative temperature anomalies over the whole Wet Pampa region (Müller et al., 2008). The simulated atmospheric circulation field favors a southerly anomalous wind component, which is the synoptic situation that causes frosts due to the cold and dry air advection. The result of the experiment in the $-\sigma$ basic state with the heat source located at the same position as in the previous experiment, shows a different configuration. The surface temperature anomalies are negative to the northeast of the region and are positive over the remaining area. The low level circulation does not create a favorable condition for the occurrence of frosts because part of the Wet Pampa is dominated by a south-southeasterly wind component that brings maritime air into the region. The results suggest that stationary Rossby waves may be an important mechanism linking anomalous tropical convection with the extreme cold events in the Wet Pampa.

The numerical experiments in the $+\sigma$ basic state (Müller et al., 2008) indicate that the extension of the anticyclonic region and the cold advection over SSA when the heat forcing is placed over the western Pacific Ocean, are similar to that observed by Müller et al. (2005) during the $+\sigma$ winters. However, the amplitudes seem to be insufficient to generate the mass field and motion field anomalies observed by Müller et al. (2005) from a composite of GF selected within the $+\sigma$ winters. Instead, when the heat forcing is placed over the western South Indian Ocean, the expected wave pattern observed during these events is achieved. The results obtained by Müller and Ambrizzi (2007) indicate the existence of a double train of Rossby waves which propagate along the subtropical and polar jets, respectively, whose phases coincide just before reaching South America. This pattern generates a strong polar air advection over the southern cone of the continent with the consequent decrease in surface temperature accompanied by large areas with GF in the region. This interesting feature of these wave trains phase coincidence just before reaching South America, besides of being observed in the composite of winters with maximum frequency of GF occurrence (Müller et al., 2005), it was also observed in the composite of the most persistent GF events (higher than two consecutive days of GF, Müller and Berri, 2007). These authors grouped the GFs according to their persistence, which is defined as the number of consecutive days that follows the first day of the event and comply with the GF condition.

The question which arises from the analyses of the extreme winter composite with respect to the frequency of GF occurrence is whether the obtained features are inherent to those particular winters or they are found in the average winter. In order to answer this question, simulations equivalent to those of Müller and Ambrizzi (2007) and Müller et al. (2008) are performed with the forcing located in the Indian and Pacific Oceans, respectively. The numeric experiments consider the mean winter (June, July and August) of the 1961-1990 period as the basic state, from which the $+\sigma$ and $-\sigma$ winters are obtained.

\section{Data and methodology}

The numerical simulations utilize the same model as in the previous study by Müller et al. (2008) and Müller and Ambrizzi (2007) for the $+\sigma$ and $-\sigma$ basic states. The Intermediate Global Circulation Model (IGCM) used in the numerical experiment was developed by Hoskins and Simmons (1975) and has been extensively used in teleconnection studies (see Ambrizzi and Hoskins, 1997, and references there). The IGCM is spectrally truncated with a total zonal wave number T42, it has 12 vertical sigma levels, an also includes horizontal and vertical diffusion and Newtonian cooling. For the initial condition the NCEP-NCAR Reanalysis Project is used, available on a $2.5^{\circ} \times 2.5^{\circ}$ resolution grid, and provided by NOAA-CIRES. The input variables that the model uses are geopotential height, zonal and meridional wind and temperature.

The utilized thermal forcing has an elliptical horizontal structure and the vertical heating profile that follows a cosine function with maximum amplitude at $400 \mathrm{hPa}$. The experiments consider the forcing given by a heat source in the Pacific Ocean which simulates the observed convection in the $+\sigma$ and $-\sigma$ composites obtained by Müller et al. (2008). They are calculated as outgoing longwave radiation (OLR) anomalies with respect to the 1974-1996 mean value, provided by NOAA-CIRES. Another experiment considers the forcing located in the Indian Ocean, following Müller and Ambrizzi (2007), which simulates the Rossby wave patterns previously observed in $+\sigma$ composite by Müller et al. (2005).

Theory shows that the response to the tropical heating is baroclinic in the vicinity of the forcing and barotropic far from the source (Ambrizzi and Hoskins, 1997). This can be seen through vertical cross-section analysis for a given latitude. The numerical results obtained by Müller and Ambrizzi (2007) and Müller et al. (2008), indicated that the response of the heating source placed in the different latitudes and longitudes shows an equivalent barotropic Rossby wave for the $+\sigma$ and $-\sigma$ basic states and there was no baroclinic instability development during the days integration period. The results of the experiments are shown on the day the solution acquires quasi stationary pattern. In the experiments on the Pacific Ocean it takes 10 days and for the Indian Ocean experiment it takes 14 days. 

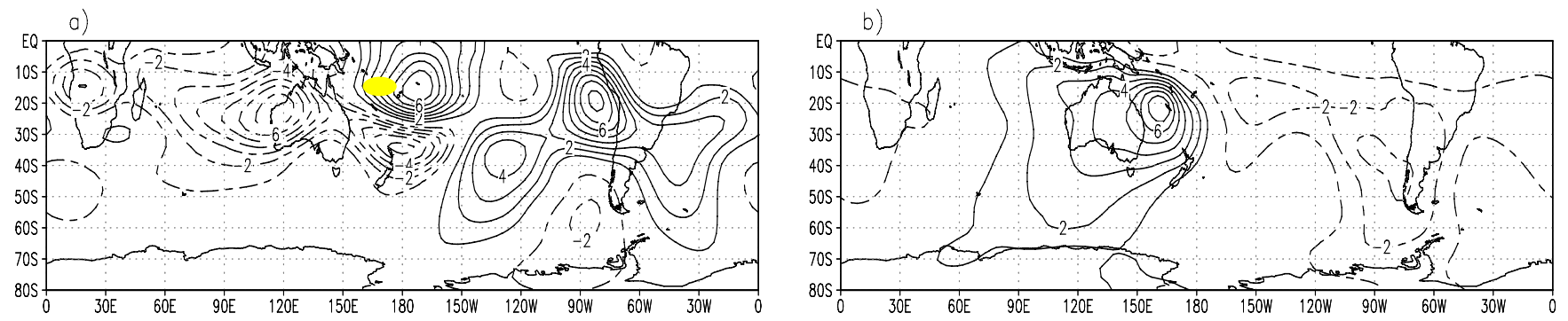

Fig. 1. Stream function anomalies $\left(1 \times 10^{-6} \mathrm{~m}^{2} \mathrm{~s}^{-1}\right)$ at $250 \mathrm{hPa}$ (a) and $850 \mathrm{hPa}(\mathbf{b})$, on day 10 of integration, corresponding to the mean winter state basic experiment with a forcing at $170^{\circ} \mathrm{E}-15^{\circ} \mathrm{S}$ (see dot in the figure).

\section{Results}

This section presents the results obtained in the different numerical simulations in the mean winter basic state and are compared to those obtained by the simulations using the $+\sigma$ and $-\sigma$ basic states. With respect to these basic states, it is necessary to mention that the $+\sigma$ and $-\sigma$ experiments were previously analyzed for the forcing in the Indian Ocean by Müller and Ambrizzi (2007), and for the forcing in the Pacific Ocean by Müller et al. (2008). However, the discussion in the latter was focused mainly on $+\sigma$ basic state, reason why in this paper the results for the simulations in $-\sigma$ basic state are presented as a complement to the mean winter basic state.

\subsection{Experiment with Pacific Ocean forcing}

The OLR anomaly field for the $+\sigma$ winters composite obtained by Müller et al. (2008) shows two main regions of anomalous tropical convection in the Southern Hemisphere, with significant values, which are situated in the Indian and western Pacific Oceans, respectively. On the other hand, in the $-\sigma$ winters composite there are regions with negative OLR anomalies in the Southern Pacific Ocean and the main one is located at $120^{\circ} \mathrm{E}-15^{\circ} \mathrm{S}$ (Müller et al., 2008). This section presents the experiments in the mean winter basic state with the same forcing observed in the Pacific Ocean in the $+\sigma$ and $-\sigma$ composites. These forcing corresponds to the anomalous convection observed at $170^{\circ} \mathrm{E}-15^{\circ} \mathrm{S}$ in the $+\sigma$ winters and at $120^{\circ} \mathrm{E}-15^{\circ} \mathrm{S}$ in the $-\sigma$ winters. Following Müller et al. (2008) the anomaly patterns to be shown from the numerical results are obtained from the difference between the day 10 of integration and day 0 , which represent the basic state before the heating forcing is initiated.

\subsubsection{Experiment with forcing in $170^{\circ} \mathrm{E}-15^{\circ} \mathrm{S}$}

Figure 1a shows the anomalies of the stream function aloft with large amplitude in the western part hemisphere and a phase opposition between the tropics and subtropics in the South Pacific Ocean. To the extreme south-southwest of the continent, an anticyclonic anomaly is located approximately

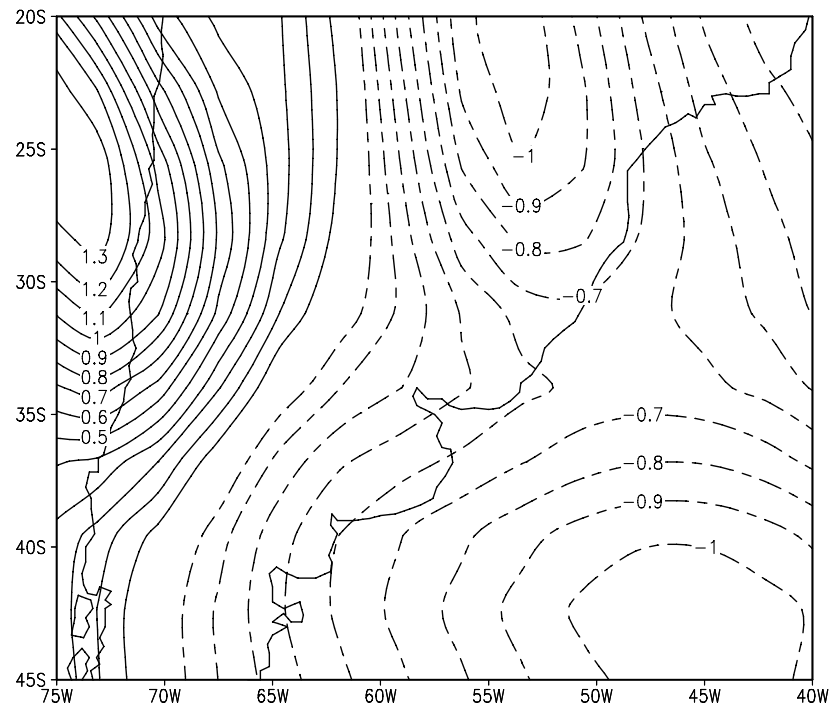

Fig. 2. Surface temperature anomalies $\left({ }^{\circ} \mathrm{C}\right)$ on day 10 of integration corresponding to the mean winter basic state experiment with the forcing at $170^{\circ} \mathrm{E}-15^{\circ} \mathrm{S}$

at $90^{\circ} \mathrm{W}$. This same anomaly is observed in the $850 \mathrm{hPa}$ field (Fig. 1b) which extends its influence over the entire southern cone. Consequently, negative surface temperature anomalies are observed over eastern Argentina and positive anomalies to the west (Fig. 2). The circulation generated by this configuration is clear in the $850 \mathrm{hPa}$ wind anomalies pattern (Fig. 3b). The region with southerly advection is circumscribed to eastern Argentina. In this figure is appreciated that the response to the tropical heating is baroclinic in the vicinity of the forcing and barotropic far from the source, with was previously mentioned (Sect. 2). In the left panel (Fig. 3a) a positive meridional wind anomaly is observed at $250 \mathrm{hPa}$ covering the same area of the country. It is part of a wave train that propagates from the source region in the western Pacific Ocean towards the South Atlantic Ocean, with another wave train identified at subtropical latitudes. They together form a double wave train that propagates across the Pacific Ocean, in agreement with the results found by other authors for the Southern Hemisphere winter (e.g. Ambrizzi 

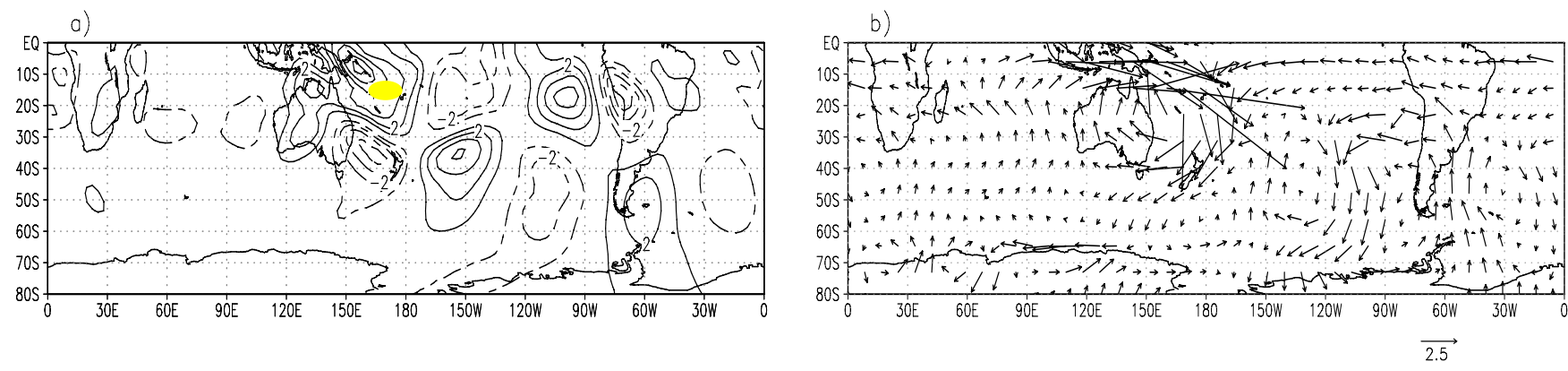

Fig. 3. Meridional wind component anomalies $\left(\mathrm{ms}^{-1}\right)$ at $250 \mathrm{hPa}$ (a) and wind vector anomaly at $850 \mathrm{hPa}(\mathbf{b})$, on day 10 of integration, corresponding to the mean winter basic state experiment with the forcing at $170^{\circ} \mathrm{E}-15^{\circ} \mathrm{S}$ (see dot in the figure).
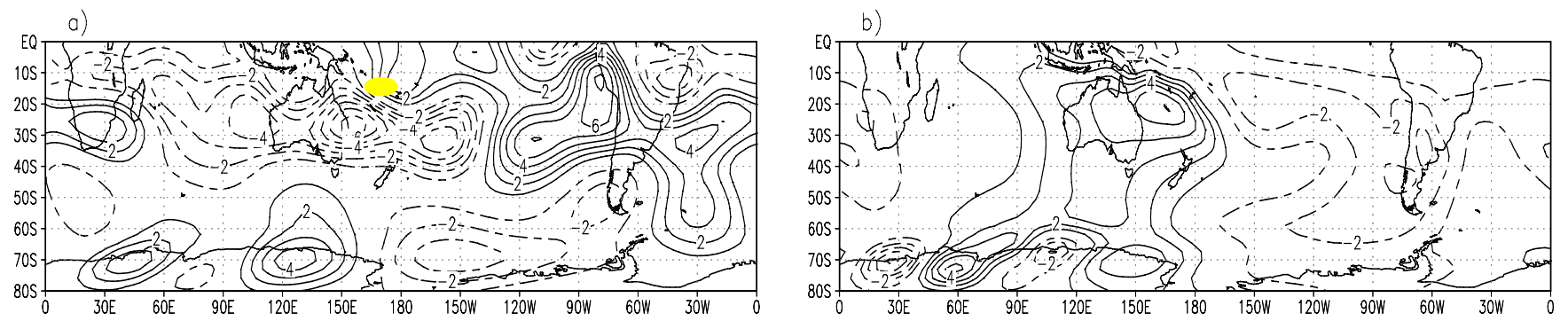

Fig. 4. Stream function anomalies $\left(1 \times 10^{-6} \mathrm{~m}^{2} \mathrm{~s}^{-1}\right)$ at $250 \mathrm{hPa}(\mathbf{a})$ and $850 \mathrm{hPa}(\mathbf{b})$, on day 10 of integration, corresponding to $-\sigma$ basic state experiment with the forcing at $170^{\circ} \mathrm{E}-15^{\circ} \mathrm{S}$ (see dot in the figure).

et al., 1995), which demonstrate that the jets act as wave guides. This pattern aloft does not resemble the one simulated for the basic state $+\sigma$, nor does with the low level circulation (see Fig. 2 from Müller et al., 2008). The difference is given by the origin of the anomalous wind over the region of interest. Although the meridional wind anomalies for both experiments ( $+\sigma$ and mean winter) are from the south, in the one observed for the mean winter basic state the polar air crosses an extended maritime region before reaching the Wet Pampa (Fig. 3), while in the $+\sigma$ experiment the flow is mainly continental and therefore drier (see Fig. 2 from Müller et al., 2008).

It is interesting to compare the simulation of the mean winter basic state with that of the equivalent experiment in $-\sigma$. The movement field aloft of the simulation in the mean winter basic state shows a similar configuration to the equivalent experiment in $-\sigma$ (see Fig. 4a and Fig. 1a). This similarity is also observed at low levels particularly in the southernmost part of the continent, where an anticyclonic anomaly is observed over Patagonia. However, the relative position of this anomaly differs in both experiments; in the mean winter basic state it is localized west of the continent (Fig. 1b) while is over the continent in $-\sigma$ basic state (Fig. $4 b$ ). This anomaly creates a circulation with a southeast component and advection of maritime air, and therefore, a more humid situation over the Wet Pampa region. They are not the most favorable conditions for the occurrence of frost. However, the northern region of the Wet Pampa will have favorable conditions for the formation of radiative frosts, given that another anticyclonic anomaly is located in the central-northeastern region of Argentina (Fig. 4b). The proportion of the Wet Pampa covered by this effect is not enough to create a generalized frost, and are reduced to partial or isolated frosts (Müller, 2007).

\subsubsection{Experiment with forcing in $120^{\circ} \mathrm{E}-15^{\circ} \mathrm{S}$}

In this experiment, in the mean winter basic state, the mass field shown in Fig. 5a-b presents a negative stream function anomaly which extends over most of South America, in particular at the $850 \mathrm{hPa}$ level (Fig. 5b). It is interesting to compare with the configuration obtained with the $-\sigma$ basic state of the same experiment (Fig. 6a-b). At first sight, both configurations are similar (Figs. 5 and 6), but taking a closer look at South America, interesting differences can be found. Figure 6a, which corresponds to $250 \mathrm{hPa}$, highlights a pattern clearly defined by the stream function anomalies in the Pacific Ocean along $30^{\circ} \mathrm{S}$. However, upon reaching South America, the anomalies project northeastwards, while to the south and over the continent, they are practically inexistent. At high latitudes, in the same figure, a large area is dominated by negative anomalies. Centered at $120^{\circ} \mathrm{W}$, this area extends throughout the troposphere (Fig. 6b) in coincidence with the persistent negative anomaly at $120^{\circ} \mathrm{W}$ and $60^{\circ} \mathrm{S}$ observed 

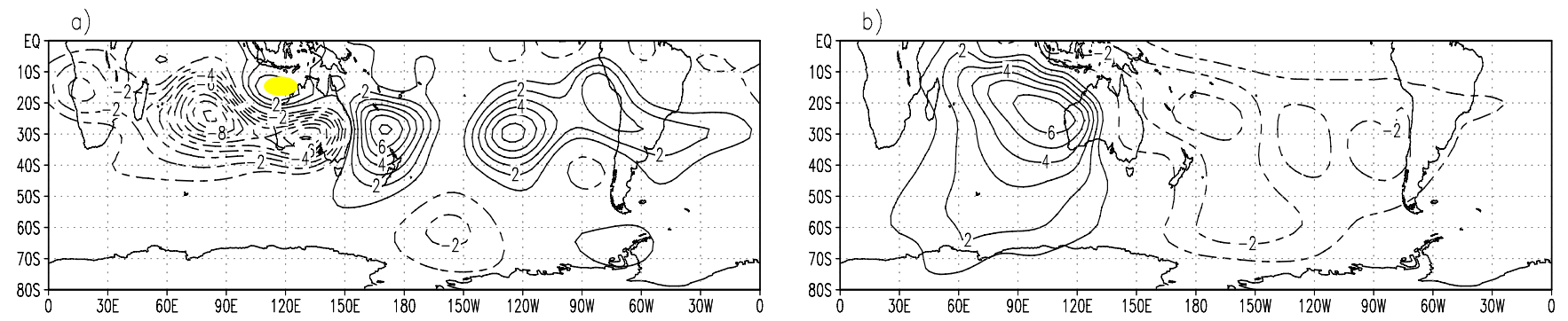

Fig. 5. Stream function anomalies $\left(1 \times 10^{-6} \mathrm{~m}^{2} \mathrm{~s}^{-1}\right)$ at $250 \mathrm{hPa}$ (a) and $850 \mathrm{hPa}(\mathbf{b})$, on day 10 of integration, corresponding to the mean winter basic state experiment with the forcing at $120^{\circ} \mathrm{E}-15^{\circ} \mathrm{S}$ (see dot in the figure).
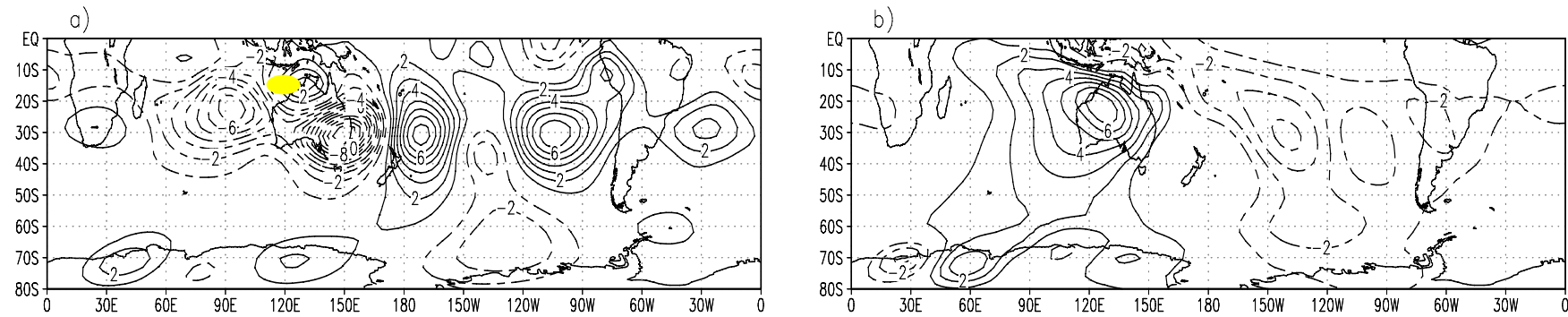

Fig. 6. Stream function anomalies $\left(1 \times 10^{-6} \mathrm{~m}^{2} \mathrm{~s}^{-1}\right)$ at $250 \mathrm{hPa}(\mathbf{a})$ and $850 \mathrm{hPa}(\mathbf{b})$, on day 10 of integration, corresponding to $-\sigma$ basic state experiment with the forcing at $120^{\circ} \mathrm{E}-15^{\circ} \mathrm{S}$ (see dot in the figure).

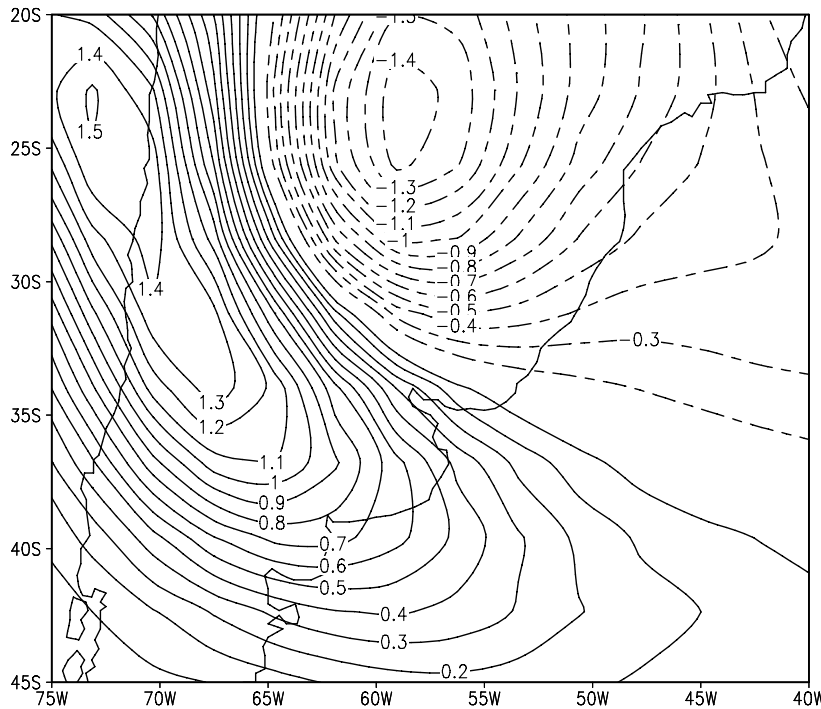

Fig. 7. Surface temperature anomalies $\left({ }^{\circ} \mathrm{C}\right)$ on day 10 of integrations, corresponding to $-\sigma$ basic estate experiment with the forcing at $120^{\circ} \mathrm{E}-15^{\circ} \mathrm{S}$.

by other authors during the austral winter, e.g. Mo and Higgins (1998).

Over the continent and at low levels $(850 \mathrm{hPa})$, a negative anomaly affects the northeast of the Wet Pampa, as can be seen in Fig. 6b. This is linked to the negative surface temperature anomalies over northeastern Argentina (Fig. 7). In this

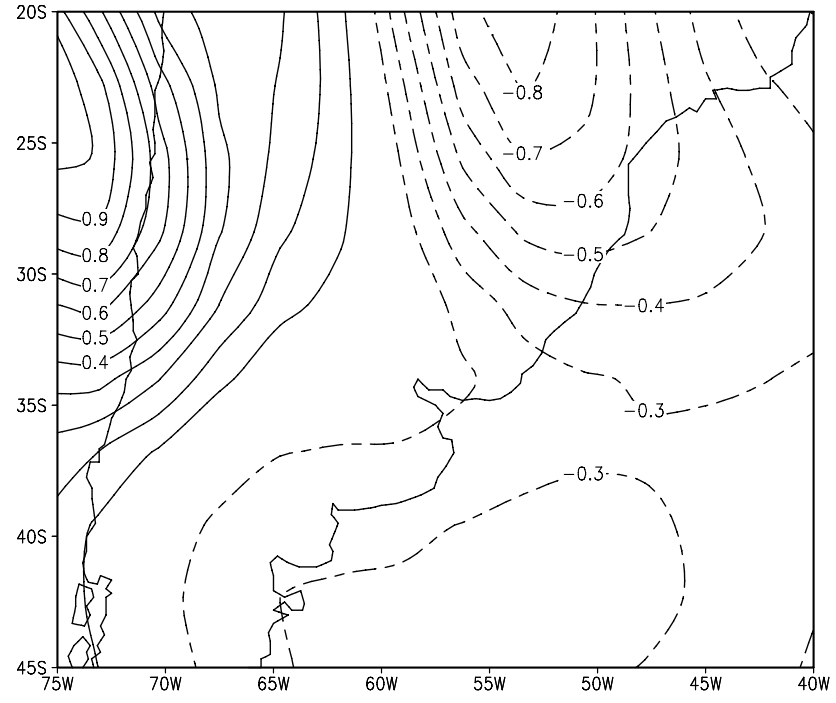

Fig. 8. Surface temperature anomalies $\left({ }^{\circ} \mathrm{C}\right)$ on day 10 of integration, corresponding to the mean winter basic state experiment with the forcing at $120^{\circ} \mathrm{E}-15^{\circ} \mathrm{S}$.

simulation of the $-\sigma$ basic state, the temperature decrease in the northeast of the Wet Pampa would eventually cause frosts. However, given their spatial extension, they cannot be considered generalized frosts, but rather partial or isolated frosts as studied by Müller (2007). This is in contrary to what it is observed in Fig. 8 for the mean winter basic 

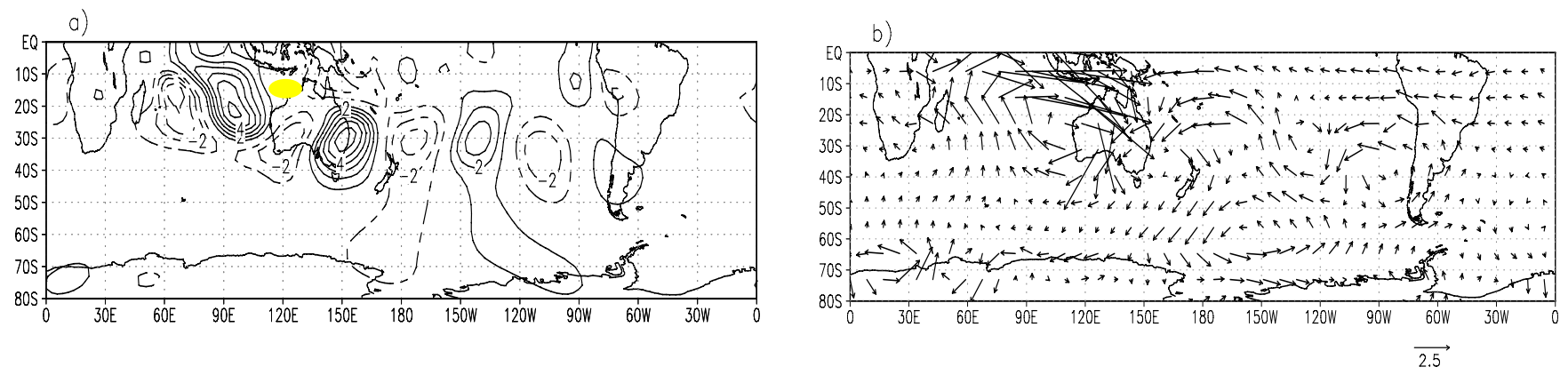

Fig. 9. Meridional wind component anomalies $\left(\mathrm{ms}^{-1}\right)$ at $250 \mathrm{hPa}(\mathbf{a})$ and wind vector anomaly at $850 \mathrm{hPa}(\mathbf{b})$, on day 10 of integration, corresponding to the mean winter basic state experiment with the forcing at $120^{\circ} \mathrm{E}-15^{\circ} \mathrm{S}$ (see dot in the figure).

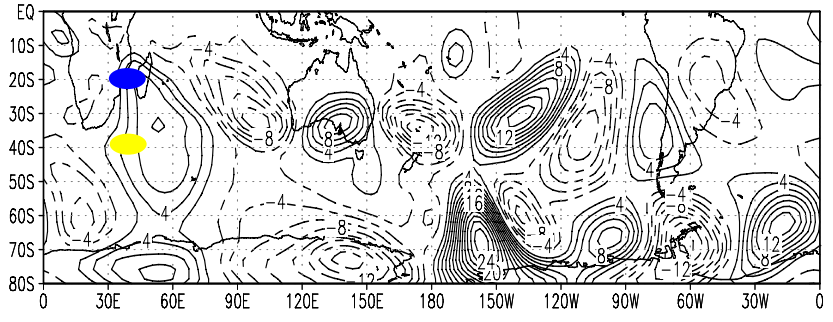

Fig. 10. Meridional wind component anomalies $\left(\mathrm{ms}^{-1}\right)$ at $250 \mathrm{hPa}$ on day 14 of integration, corresponding to the mean winter basic state experiment with the forcing at $40^{\circ} \mathrm{E}-20^{\circ} \mathrm{S}$ and $45^{\circ} \mathrm{E}-40^{\circ} \mathrm{S}$ (see dots in the figure).

state, with negative temperature anomalies over most of Wet Pampa. These anomalous temperature values are explained by the west-southwesterly advection (Fig. 9b), which mainly affects Atlantic Ocean coast of Argentina. In Fig. 9b is appreciated that the response to the tropical heating is baroclinic in the vicinity of the forcing and barotropic far from the source, such as in the Fig. 3b. The left panel in Fig. 9 shows the meridional wind anomalies with a wave train that propagates following the subtropical jet until the eastern Pacific Ocean, continuing then its trajectory towards the south of South America. This pattern for the mean winter is similar to the one shown in Müller et al. (2008, Fig. 9a) for the same experiment in the $-\sigma$ basic state, except that in the mean winter experiment a positive meridional wind anomaly covers the south of South America (Fig. 9a).

It is worth mentioning that the OLR anomaly field for the $+\sigma$ winters composite shows in $120^{\circ} \mathrm{E}-15^{\circ} \mathrm{S}$ a region where convection is inhibited (see Fig. 1a, Müller et al., 2008). Hence, the equivalent experiment in the $+\sigma$ basic state lacks physical meaning since it will not create a perturbation in the forcing position.

\subsection{Experiment with Indian Ocean forcing}

The numeric experiment for the mean winter basic state, with the forcing in the same position as in Müller and Ambrizzi
(2007), is presented. The first forcing coincides with one of the South American teleconnection points $\left(40^{\circ} \mathrm{E}-20^{\circ} \mathrm{S}\right)$, i.e. the region immediately upstream of the subtropical jet stream principal maximum over the tropical Indian Ocean. It must be pointed out that, since the forcing is located in the tropical region, it would be simulating a heat source due to deep convection. Instead, the second forcing located in mid latitudes $\left(45^{\circ} \mathrm{E}-40^{\circ} \mathrm{S}\right)$, it is simply used in order to create a perturbation of the basic state, known as a wave maker. This forcing should not be considered as isolated sources at mid latitudes but rather as a thermal gradient, in other words the purpose of the forcing is to increase the thermal gradient. Following Müller and Abrizzi (2007) the anomaly patterns to be shown from the numerical results are obtained from the difference between the day 14 of integration and day 0 , which represent the basic state before the heating forcing is initiated.

The results in Fig. 10 show a double wave train which propagates independently along the subtropical and polar jet streams with no phase coincidence. Waves propagating at high latitudes follow a purely zonal trajectory and further south than the analysis of Müller and Ambrizzi (2007) for the $+\sigma$ and $-\sigma$ basic states. However, the one corresponding to subtropical latitudes curves its trajectory approximately over the central Pacific Ocean, entering South America at mid latitudes and continuing in the northeast direction.

The configuration found in the mean winter simulation is similar to the one obtained for the composite of observed events with 1 day persistence of GF, or less persistent GF events (see Fig. 4 from Müller and Berri, 2007). The main difference is the value of the anomalies which in the observed composite is twice than those simulated, as well as the latitude of propagation. The observed wave train enters the continent in southwestern South America, while in the simulated case it does further north (Fig.10). This indicates that, although the result of the experiment coincides in the typical arc shaped trajectory that enters the South American continent causing the widely discussed cold outbreaks, it does not seem to be sufficient to cause the GF. According to the observations, the GF generated under similar conditions to those 

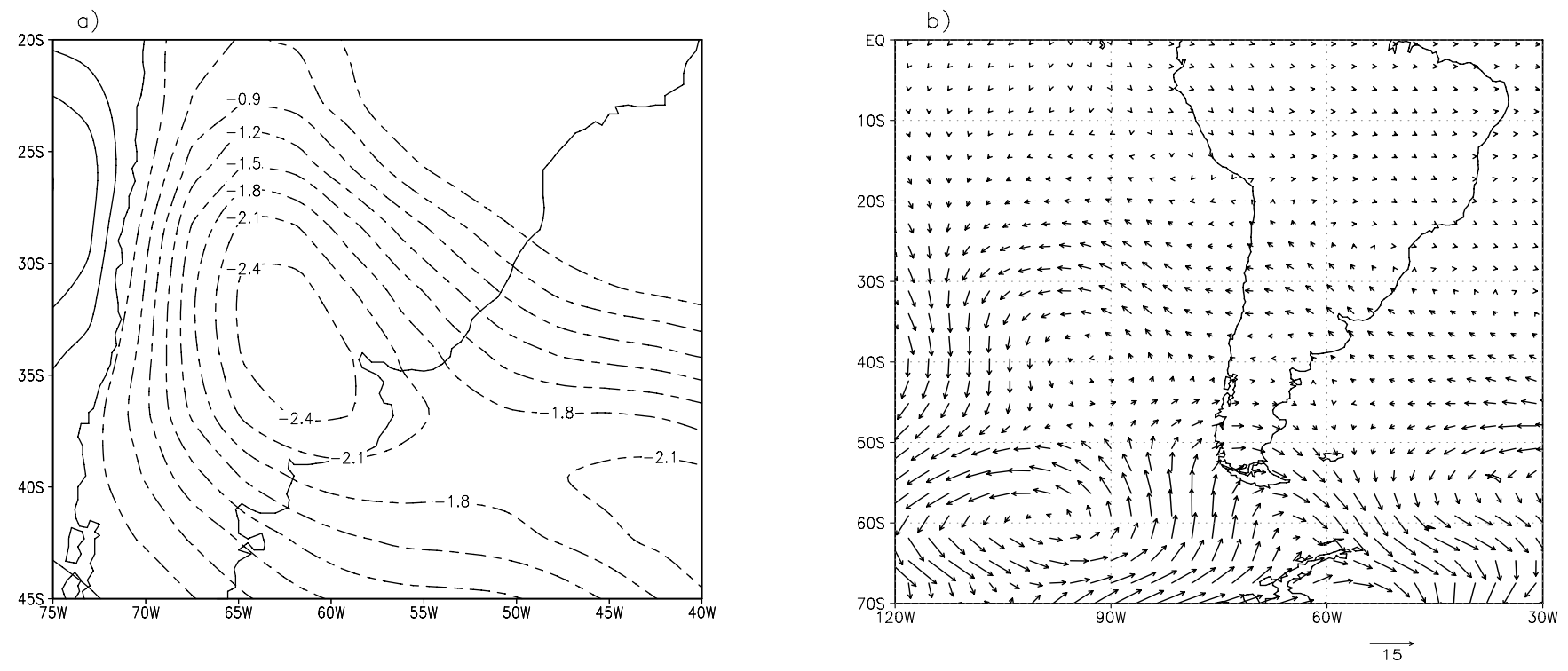

Fig. 11. Surface temperature anomalies $\left({ }^{\circ} \mathrm{C}\right)$ (a) and wind vector anomaly $\left(\mathrm{ms}^{-1}\right)$ at $850 \mathrm{hPa}(\mathbf{b})$, on day 14 of integration, corresponding to the mean winter basic state experiment with the forcing at $40^{\circ} \mathrm{E}-20^{\circ} \mathrm{S}$ and $45^{\circ} \mathrm{E}-40^{\circ} \mathrm{S}$.

simulated - at least with respect to the propagation pattern -, need to acquire an amplitude and intensity such that, besides entering through the southwest of the continent, would be able to guarantee the duration of the system. The mentioned large scale features will facilitate a continuous southerly advection, inducing extended advective frosts.

On the other hand, it is interesting to point out that the characteristics of the propagation trajectories in the mean winter (Fig. 10) are opposed to those obtained in the $+\sigma$ experiment of Müller and Ambrizzi (2007). In that case, the purely zonal trajectory corresponds to the subtropical latitude wave train, while the waves which propagate in polar latitudes (see Fig. 5a from Müller and Ambrizzi, 2007) acquire a certain meridional component near the continent. In the present simulation the surface temperature anomalies are negative (Fig. 11a), as well as in the $+\sigma$ and $-\sigma$ basic states (see Figs. 7 and 9a from Müller and Ambrizzi, 2007), although the anomalous wind circulation at $850 \mathrm{hPa}$ over the Wet Pampa region is mainly from the eastern sector (Fig. 11b). Therefore, the temperature decrease would not trigger frosts because the advection is mainly of moist air.

\section{Discussion and conclusions}

This paper investigates the role that tropical anomalous convection over the western Pacific Ocean and South Indian Ocean plays in the generation of extratropical wave patterns that cause a temperature decrease in the Wet Pampa, during the winters of the period 1961-1990. A baroclinic global circulation model is employed to study the response to an excitation caused by the presence of heat sources in the regions where OLR anomalies are observed in the composites of the winters with maximum and minimum frequency of GF occurrence ( $+\sigma$ and $-\sigma$ respectively). It is assumed that such events are not caused by local conditions but they are the response to larger scale processes. It is also analyzed the answer to a forcing which generates a propagation pattern in agreement with the observed patterns in the composite of the most conspicuous (most frequent and more persistent) GF events. The wave patterns and the atmospheric circulation fields resulting from these simulations in the mean winter basic state are compared to other basic states which represent winters with the extreme frequency of GF occurrence, i.e., $+\sigma$ and $-\sigma$.

When the forcing is in the Pacific Ocean, in particular at $170^{\circ} \mathrm{E}-15^{\circ} \mathrm{S}$ (which corresponds to the observed anomalous convection in the $+\sigma$ basic state), the experiment in the mean winter basic state shows a Rossby wave propagation pattern different to those of the $+\sigma$ and $-\sigma$ basic states. The experiment in the $+\sigma$ basic state presents a Rossby wave pattern with an arc shaped trajectory that initially moves polewards and later deflects towards the equator (Müller et al., 2008). This wave train reaches South America in its central part and creates a southerly wind anomaly in the southern part of the continent. Instead, the propagation pattern of the $-\sigma$ basic state experiment does not agree with the preferential paths that waves follow in the Southern Hemisphere during the austral winter (Müller et al., 2008). This is due to the fact that two wave trains are observed which split at the region of origin; the northern one reaches the South American continent at equatorial latitudes, while the other one moves towards the South Atlantic. In the mean winter basic state two wave trains are observed, but they propagate along the 
subtropical and polar jet streams, respectively. Despite the trajectories of these wave trains differ from those found in $-\sigma$, both basic states create the same anomaly configuration over the continent. In both the $-\sigma$ and the mean winter, in particular the waves propagating at high latitudes rapidly cross the southern part of the continent and therefore do not generate favorable conditions for the formation of GF. This clearly indicates that the $+\sigma$ winters have typical characteristics which explain the maximum frequency of occurrence of GF that distinguish them from the averaged winters. It is important to point out that this result refers to a particular forcing position which can be associated with the "warm Pacific Ocean pool", a region of frequent convective activity.

The second experiment in the $-\sigma$ basic state with the forcing $120^{\circ} \mathrm{E}-15^{\circ} \mathrm{S}$, that corresponds to the observed anomalous convection in the same basic state, shows surface temperature anomalies that are negative to the north of the Wet Pampa and positive in its central and southern region. The low level circulation is typical of radiative frosts, but without being generalized since the anticyclonic anomaly is circumscribed to a smaller area inside the Wet Pampa. The motion field aloft shows a wave train that follows the subtropical jet. This result is also in agreement with the Rossby wave propagation theory since, in particular for short waves, the propagation path follows a latitudinal circle at subtropical latitudes. A weakening of the wind anomalies is observed when the wave train reaches South America. At this position, but at low levels, there is a northern wind anomaly that interferes with the cold air advection from the south, windward of the Andes Mountains. These wind fields are shown in Müller et al. (2008, Fig. 9). On the other hand, the result of the experiment with the same forcing but in the mean winter basic state presents a wave train similar to that of the $-\sigma$ basic state, except that it reaches the continent at mid to high latitudes, with a southerly meridional wind anomaly. At low levels the air advection from the southwest, and the consequent negative temperature anomalies, seem to affect mainly the eastern sector of the study area.

The predominant Rossby wave trains of the experiments with the forcing in the Indian Ocean for the analyzed basic states show propagation at both polar and subtropical latitudes. The patterns found are not in phase when they reach South America, neither in the mean winter nor in the $-\sigma$ simulation, as observed in the $+\sigma$ simulated by Müller and Ambrizzi (2007). Moreover, divergence is observed between the propagation trajectories of the $-\sigma$ wave trains (Müller and Ambrizzi, 2007), as well as complete autonomy between them in the mean winter simulation. In the case of the mean winter basic state the propagation in polar latitudes is zonal. At subtropical latitudes the propagation is zonal up to the dateline where it curves southward entering the continent at mid latitudes and continuing later to the northeast.

The differences between the $+\sigma,-\sigma$ and mean winter basic states for the Indian Ocean experiment $(+\sigma$ and $-\sigma$ obtained by Müller and Ambrizzi, 2007), are observed not only in the trajectories followed by the waves, but also in the phase and amplitude that they reach when they are near the continent. For example, in the $+\sigma$ case the amplitude of the meridional wind anomalies aloft, which agree with observations, doubles the value obtained for both the $-\sigma$ and mean winter experiments. At low levels the motion field also presents discrepancies between the basic states, in spite of the similarity in the negative surface temperature anomalies simulated in each case. However, the $+\sigma$ is the only case in which a temperature decrease can lead to frosts in the Wet Pampa, since the low level circulation is mainly from the south-southwest, while the $-\sigma$ and mean winter basic states are dominated by wind anomalies from the eastern sector. In the first case, the Wet Pampa region will have favorable conditions for advective frosts because of the arrival of cold and dry air over the region. In the other two basic states the Wet Pampa region is under the influence of moist air advection which does not propitiate the occurrence of frosts.

Based on the comparative analysis between the $+\sigma,-\sigma$ and mean winter basic states, it is concluded that the features revealed by the extreme $+\sigma$ and $-\sigma$ winters are characteristic of those particular winters and do not represent the mean winter conditions. This answers the question whether the obtained features are inherent to the extreme winters composite with respect to the frequency of GF occurrence or they are found in the average winter, which motivated this work. Hence, the previously obtained results for $+\sigma$ (Müller et al., 2008), besides reproducing the patterns observed by Müller et al. (2005), explain the dynamic mechanism which leads to the most frequent GF (Müller et al., 2005) and the most persistent GF that Müller and Berri (2007) define as GF that last more than three consecutive days. This conclusion is important for the short and mid term forecast of GF, since knowing the conditions of the basic state and the dominating forcing during winter it would be possible to determine the frequency and/or persistence of the GF that could affect the Wet Pampa.

Acknowledgements. This work had partial support from CONICET (PIP-114-200801-00591). The author is grateful to the reviewers for their useful suggestions that contributed to improve the quality of this work.

Topical Editor F. D'Andrea thanks A. Pezza and another anonymous referee for their help in evaluating this paper.

\section{References}

Ambrizzi, T., Hoskins, B. J., and Hsu, H. H.: Rossby wave propagation and teleconnection patterns in the austral winter, J. Atmos. Sci., 52, 3661-3672, 1995.

Ambrizzi, T. and Hoskins, B. J.: Stationary Rossby-wave propagation in a baroclinic atmosphere, Q. J. Meteorol. Soc., 123, 919928, 1997.

Garreaud, R. D.: Cold air incursions over subtropical South America: Mean Structure and Dynamics, Mon. Weather Rev., 128, 2544-2559, 2000. 
Hoskins, B. J. and Simmons, A. J.: A multi-layer spectral model and the semi-implicit method, Q. J. Roy. Meteorol. Soc., 101, $637-655,1975$.

Krishnamurti, T. N., Tewari, M., Chakraborty, D., Marengo, J. A., Silva Dias, P. L., and Satyamurti, P.: Downstream amplification: A possible precursor to major freeze events over south-eastern Brazil, Weather and Forecasting, 14, 242-270, 1999.

Marengo, J. A., Cornejo, A., Satyamurty, P., Nobre, C., and Sea, W.: Cold surges in tropical and extratropical South America: The strong event in June 1994, Mon. Weather Rev., 125, 2759-2786, 1997.

Marengo, J. A., Ambrizzi, T., Kiladis, G., and Liebmann, B.: Upper-air wave trains over the Pacific Ocean and wintertime cold surges in tropical-subtropical South America leading to Freezes in Southern and Southeastern Brazil, Theor. Appl. Climatol., 74, 243-247, 2002.

Mo, K. C. and Higgins, R. W.: The Pacific-South American modes and tropical convection during the Southern Hemisphere Winter, Mon. Weather Rev., 126, 1581-1596, 1998.

Müller, G. V., Núñez, M. N., and Seluchi, M. E.: Relationship between ENSO cycles and frost events within the Pampa Humeda region, Int. J. Climatol., 20, 1619-1637, 2000.
Müller, G. V., Ambrizzi, T., and Núñez, M. N.: Mean atmospheric circulation leading to generalized frosts in Central Southern South America, Theor. Appl. Climatol., 82, 95-112, 2005.

Müller, G. V.: Patterns Leading to Extreme Events in Argentina: Partial and Generalized Frosts, Int. J. Climatol., 27(10), 13731387, 2007.

Müller, G. V. and Ambrizzi, T.: Teleconnection Patterns and Rossby Wave Propagation Associated to Generalized Frosts over Southern South America, Clim. Dynam., 29, 633-645, doi:10.1007/s00382-007-0253-x, 2007.

Müller, G. V. and Berri, G. J.: Atmospheric Circulation Associated with Persistent Generalized Frosts in Central-Southern South America, Mon. Weather Rev., 135(4), 1268-1289, 2007.

Müller, G. V., Ambrizzi, T., and Ferraz, S. E.: The role of the observed tropical convection in the generation of frost events in the southern cone of South America, Ann. Geophys., 26, 13791390, 2008, http://www.ann-geophys.net/26/1379/2008/.

Pezza, A. B. and Ambrizzi, T.: Dynamical Conditions and Synoptic Tracks Associated with Different Types of Cold Surges over Tropical South America, Int. J. Climatol., 25, 215-241, 2005.

Vera, C. S., Vigliarolo, P. K., and Berbery, E. H.: Cold Season Waves over Subtropical South America, Mon. Weather Rev., 130 684-699, 2002. 